\title{
OS POEMAS HOMÉRICOS E O CONCEITO DE TRADIÇÃO
}

\author{
Gustavo Junqueira Duarte Oliveira ${ }^{1}$
}

\begin{abstract}
Resumo
O tema deste artigo é a tradição poética da qual os poemas homéricos fazem parte. Em um primeiro momento, propus uma discussão teórica sobre o conceito de tradição. Enfatizei os aspectos da transmissão de determinados conteúdos pensados como relacionados ao passado de determinados grupos, bem como a valorização específica destes elementos por estes grupos. Em seguida, busquei apresentar um esquema de interação entre aspectos diferentes no interior de uma mesma tradição, ou entre tradições diferentes. Na parte principal do artigo, delimitei a tradição à qual os poemas homéricos pertencem e a posição que nela ocupam. A discussão aqui proposta abrange a apresentação de vários fenômenos que podem ser identificados com esta tradição, desde os poéticos, como a poesia hexamétrica grega, até os iconográficos, em especial na pintura de vasos a partir do século VIII². Por fim, o artigo se encerra com uma pequena discussão sobre como os poemas homéricos podem ser vistos como testemunhos desta tradição mais ampla.
\end{abstract}

\section{Palavras-chave}

Homero; poesia grega; tradição.

\footnotetext{
${ }^{1}$ Professor Doutor, Faculdade de São Bernardo do Campo - São Bernardo do Campo, SP, Brasil. email: gustavojdo@gmail.com

2 Agradeço a Tatiana Faia, Camila Aline Zanon e Ana Paula Bezerra Severiano pelas sugestões e correções que em muito beneficiaram este artigo. Todas as referências a séculos neste artigo dizem respeito a períodos anteriores a nossa era, salvo indicação do contrário.
} 


\begin{abstract}
This paper focuses on the poetical tradition to which the Homeric poems belong. Firstly, I present a theoretical discussion regarding the concept of Tradition. The emphasis is on the transmission of content thought as relating to the past of certain groups, as well as the specific ways in which those groups value such elements. Secondly, the paper presents an interaction scheme between different aspects inside one tradition, or between different traditions. Finally, in the main section of the paper, I discuss the tradition the Homeric poems belong to, as well as the role the poems play in it. This discussion covers several phenomena that can be identified with the tradition, from the poetical ones, such as the Greek hexametrical poetry, to the iconographic ones, especially vase paintings from the eighth century ${ }^{3}$ onwards. I conclude with a brief discussion on how the Homeric poems can be used as testimony to this broader tradition.
\end{abstract}

\title{
Keywords
}

Homer; Greek poetry; tradition.

\footnotetext{
${ }^{3}$ I would like to thank Tatiana Faia, Camila Aline Zanon and Ana Paula Bezerra Severiano for many invaluable suggestions and corrections that improved the present paper. All the references to centuries in this paper refer to periods before the Current Era, save mentions to the contrary.
} 


\section{O conceito de tradição}

a) O que é tradição?

Devo começar este artigo com um alerta. Não pretendo aqui definir tradição de uma maneira que abranja a multiplicidade de usos que o conceito permite, tais como a relação entre tradição e modernidade, ou a invenção de tradições. Esse tipo de abordagem será mencionado, mas os detalhes de suas argumentações podem ser encontrados em estudos como os de Shiels (1981) e nas coletâneas de Hobsbawm e Ranger (1997) ou de Phillips e Schochet (2004). Meu objetivo é compreender uma ideia de tradição que remeta a um tipo específico que me proponho investigar. Ainda assim, espero que o exposto aqui possa ser útil a interessados de outras áreas. Estudos que se propõem a definir este conceito, de maneira ampla ou específica, continuam em falta.

Inicialmente, entendo por tradição um fenômeno de transmissão através do tempo de características e conteúdos relativos a uma comunidade humana. Tais elementos são mantidos pelos membros dessa comunidade, por um esforço que vai além da simples repetição. Associada à transmissão, está uma valorização específica, em geral positiva, dos elementos transmitidos.

A definição do termo por Shiels começa com a constatação de que ele pode ter muitos sentidos. O mais básico é o de qualquer coisa transmitida do passado para o presente (Shiels, 1981: 12-17). Muitas tradições apresentam um elemento normativo, uma crença ou forma de conduta apresentada para ser aceita. $\mathrm{O}$ aspecto normativo pode ser uma força inercial que mantém junta uma sociedade de uma dada maneira através do tempo (Sheils, 1981: 23-25).

Para Lenclud, o conceito tem sido pouco delimitado. Um dos elementos relevantes de seu uso é, inicialmente, a associação da palavra tradição com o tempo. Essa relação evoca o adjetivo ancestral, ou mesmo imemorial. Uma tradição é algo do passado persistente no presente. A ideia veiculada pela tradição, portanto, é uma de antiguidade e continuidade que parece ter sido seguida de maneira ininterrupta (Lenclud, 1994: 2629).

Esse ponto de vista, contudo, é insuficiente. Nem sempre a tradição é criada por sua antiguidade. Pode-se, inclusive, formular o contrário: a tradição fabrica o sentimento de antiguidade. Para Lenclud, a ideia de tradição tem sido pensada como algo determinado pelo presente e não pelo passado. É a concepção da invenção da tradição, segundo a qual ela é 
uma resposta, encontrada no passado, de questões formuladas no presente. Uma tradição seria uma retórica daquilo que deveria ter sido, um ponto de vista retrospectivo (Lenclud, 1994: 29-34).

Essa perspectiva tornou-se notória a partir da coletânea organizada por Hobsbawm e Ranger (1997). Na introdução, o primeiro autor defende que uma tradição inventada tenta traçar uma continuidade com o passado que pode operar de forma bastante artificial. As tradições inventadas seriam reações a situações novas que assumem a forma de referência a supostas situações anteriores (Hobsbawm; Ranger, 1997: 9-12).

Como crítica à posição de Ranger e Hobsbawm, há os textos da coletânea de Phillips e Schochet (2004). Na introdução, Phillips questiona o conceito de tradição inventada proposto por Hobsbawm, considerando que toda tradição é inventada, e toda tradição longeva passa por um processo de reinvenção contínua. Para o autor, uma simples oposição entre tradição verdadeira e inventada não é possível. Assim, a posição de Hobsbawm reflete uma concepção de que a tradição deve ser involuntária e inconsciente para ser genuína. Uma tradição não é necessariamente estática ou reacionária, pois pode ser adaptável, construtiva e criativa. Ações deliberadas de reviver ou manter tradições não são necessariamente invenção de novas tradições (Phillips; Schochet, 2004: 47).

Por sua vez, Schochet, no capítulo final da mesma coletânea, propõe que também é importante distinguir a posição do sujeito em relação à determinada tradição. A perspectiva interna diz respeito aos seus participantes, que agem em conformidade com ela. Para o observador externo, o recurso à tradição é explicativo e descritivo. $\mathrm{O}$ comentário interno acerca da tradição é mais prescritivo, controlando determinadas práticas (Phillips; Schochet, 2004: 305).

Lenclud sugere duas formas de ver a relação dos sujeitos com a tradição: a de culturas em que a herança do passado é produzida no presente sem que se tenha consciência disso, ou seja, sem que se tenha consciência da existência de uma escolha em romper com tal processo, consumindo-se a tradição de forma acrítica. A outra maneira (a moderna) coloca o passado à distância por meio do conhecimento. $\mathrm{O}$ sujeito pode ver sua tradição do exterior, e problematizar sua relação com o passado (Lenclud, 1994: 42).

No caso do objeto relativo a este artigo, o que temos é a primeira forma sugerida pelo autor. A tradição sobre a qual me desdobrarei mais a fundo, como veremos, não é oriunda de um contexto no qual há consciência da existência de uma escolha de romper com este processo. 
Não concordo, entretanto, que se trate apenas de um consumo acrítico de elementos pensados como do passado. No caso da poesia oral épica hexamétrica grega, tais elementos são especificamente valorizados, trabalhados e transmitidos para atingir determinados efeitos. Essa concepção segue parte das ideias sobre tradição de outro conjunto de autores.

Para Outhwaite e Bottomore, a tradição é comumente associada aos costumes que possuem considerável alcance no passado e uma espécie de aura de sagrado. Vem do verbo latino tradere, ("entregar", "transmitir", "legar à geração seguinte"). Podia se referir à transmissão de trivialidades, mas passou a ser reservada para os "depósitos" do passado que conservam um valor incomum para o presente. As tradições pertencem às mais importantes e valorizadas esferas da vida humana. Às coisas menos relevantes se reservam termos como "costumes" ou "folclore" (Outhwaite; Bottomore, 1996: 777).

Ressaltando alguns elementos já listados, Seligman e Johnson entendem que o uso do termo tradição implica um juízo de valor do que é transmitido. Alguns costumes, apesar de também transmitidos, são recebidos passivamente sem ter seu valor reforçado. Algo transmitido só se torna tradição quando se reconhece sua antiguidade e se deseja mantêla. Dessa maneira, deve ter associado a si um julgamento de valor e não somente uma repetição. A manutenção de uma tradição é a asserção desse julgamento (Seligman; Johnson, 1957: 62-63).

Procedimentos de esforço para manter formas antigas podem ser associados à inércia ou a conservadorismo, mas enquanto implicar um julgamento consciente de que os elementos antigos são melhores, trata-se de uma tradição viva. Contudo, uma tradição não implica necessariamente conservadorismo. Podem ocorrer inovações que, se aceitas, são incorporadas, além de criar outras tradições. Podem também ser vistas como fontes de desvirtuamento não ser aceitas (Seligman; Johnson, 1957: 65-67).

Dessas definições, saliento os elementos do conceito que me interessam: transmissão e valorização. Isso significa que, tal como sugere Francisco (2012: 2-3), não se trata de um processo de simples repetição formal. Trata-se de uma manutenção engajada, realizada a partir de um julgamento de valor sobre o que está sendo transmitido, a partir do ponto de vista dos próprios atores que realizam o processo de transmissão. Os agentes sociais podem até não cogitar formas de escapar da tradição, mas certamente não a transmitem de maneira acrítica. Mais do que implicar um juízo de valor, a manutenção de uma tradição não está relacionada 
somente a um processo de permanência estático de formas do passado. Novas formas podem se associar ao que é considerado tradicional, desde que valorizadas e compreendidas como válidas, reverberando uma crença em sua suposta antiguidade. Esse processo não se configura, necessariamente, como uma invenção de uma tradição, mas como uma reinterpretação de tais elementos do passado a partir da noção do presente acerca de sua pertinência.

No caso de serem verdadeiramente antigas, como as que serão meu objeto aqui, as tradições podem ser pensadas como fenômenos de longa duração, nos moldes do conceito braudeliano (Brauel, 2009). Tais fenômenos operariam de maneira a integrar contextos temporais, em que os atores sociais compartilham da valorização daquilo que compreendem como tradicional.

b) Conceito de tradições múltiplas e interconectadas: tradições dentro de tradições

Por serem fenômenos de longa duração que almejam manutenção, mas admitem mudanças, por vezes as tradições adotam novos elementos e se transformam a tal ponto que vale sugerir que são criadas novas formas no seu interior. Isso não quer dizer que o tipo originador da tradição seja necessariamente deixado de lado, mas sim que novas manifestações são aceitas e ganham, por assim dizer, vida própria. Não se trata, porém, daquilo que Ranger e Hobsbawm propõem. As formas alternativas de tradição podem abranger, incluir ou apenas se relacionar umas com as outras. Além disso, podem se suceder ou conviver paralelamente como fenômenos contemporâneos. Assim, a partir do ponto de vista do historiador, pode ser traçada uma tipologia das tradições e das transformações ocorridas no processo de desenvolvimento.

Primeiramente, temos o que vou chamar de tradições originárias. São o ponto de partida de outras tradições que delas derivam. Refiro-me tanto às tradições reais, historicamente atestadas, quanto às abstrações, isto é, os princípios lógicos. 
Denomino de derivadas as tradições que se desenvolvem a partir de tradições originárias. Todavia, o processo de derivação não ocorre necessariamente a partir de uma tradição originária. Por vezes, tradições derivadas podem originar elas mesmas outras formas. Por isso, podemos pensar em derivações indiretas, oriundas de tradições elas mesmas derivadas. Abarcando todas, podemos conceber uma tradição mais ampla. Ela conteria as demais tradições do mesmo tipo, desde a originária até as derivadas, diretas ou indiretas. Podemos representar estas interações em um diagrama explicativo:

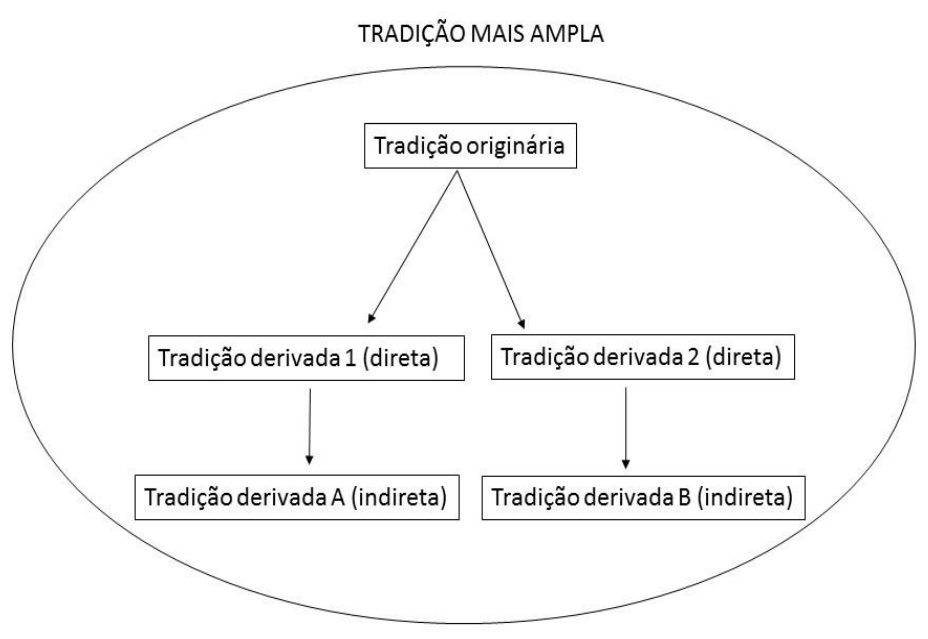

Diagrama 1 
Contudo, pensado dessa forma, se levado ao extremo, o quadro proposto acima levaria o analista a pensar as tradições de maneira engessada. $O$ que se observa é que não existe uma via de mão única. Uma tradição que precede outra que, por sua vez, dela é derivada pode ela mesma ser influenciada por aquilo que é adotado nessas novas formas de transmissão tradicional. Além disso, uma tradição pode ter mais de um elemento originador. $\mathrm{O}$ jogo de sucessão e influências é mais complexo do que aquilo que o quadro estático acima pode contemplar4. Talvez o diagrama abaixo seja uma ilustração mais útil:

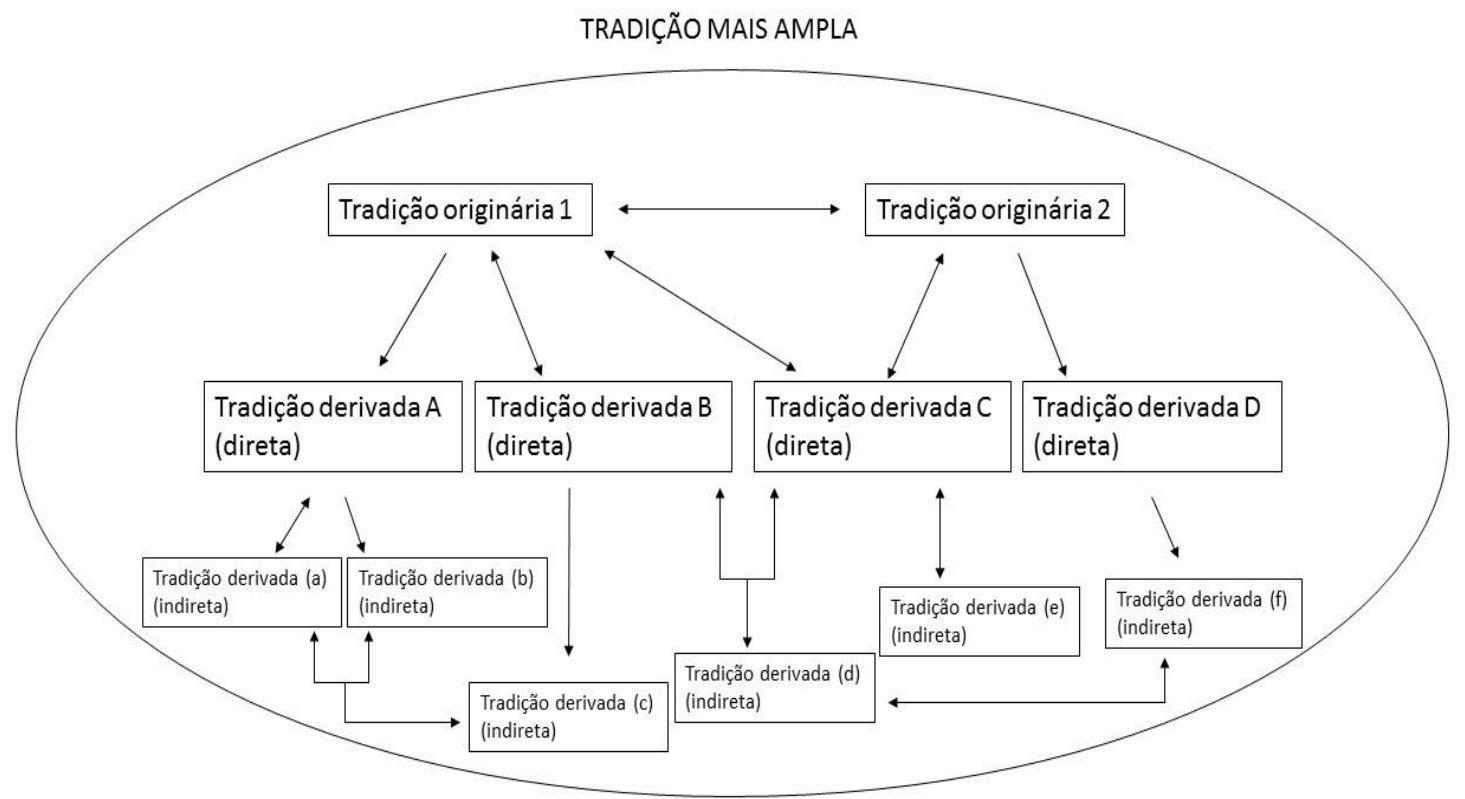

Diagrama 2

c) A tradição grega de transmissão e criação de histórias envolvendo um passado heroico e mítico

O objeto que desejo delimitar diz respeito a uma tradição específica. Trata-se da tradição grega de transmissão e criação de histórias envolvendo um passado heroico e mítico que está presente nos poemas homéricos, mas não está limitado a eles ${ }^{5}$. Tal tradição abarcaria,

4 Shiels apresenta vários processos de interação entre as tradições, seja por adição, amalgamação, absorção, fusão, bem como processos de desassociação, ramificação e desagregação (Shiels, 1981: 273-284).

${ }^{5}$ Para Scodel, o termo "tradição" é relativamente pouco discutido entre os especialistas em Homero. Diacronicamente ele costuma se referir à história e ao processo de transmissão. Referese também, sincronicamente, às regras do gênero e convenções como o dialeto poético, 
tematicamente, desde a criação deste mundo, passando pela organização dos deuses, até a idade dos heróis. Seria transportada em muitos meios: transmissão oral, em vários tipos de verso ou sem versificação; imagens em arte figurativa; textos escritos; etc.

Do ponto de vista diacrônico, a referida tradição abrange os contextos originários de tais criações (sejam eles contextos reais ou inícios lógicos), até a transmissão puramente textual escrita ou manutenção e catalogação de imagens na atualidade. Consiste em uma tradição de longuíssima duração. É importante enfatizar isso. Estamos lidando com uma tradição que, apesar de ter se transformado enormemente, continua, quase que ininterruptamente, sendo de alguma forma relevante em cada contexto.

Já na Antiguidade as transformações são observadas. Tomamos como exemplo a transmissão da poesia. Esta passou de oral à escrita na própria Antiguidade. Essa é, como dito, uma tradição muito antiga, se encarada do ponto de vista do conceito mais amplo de tradição. Ela integra os momentos mais afastados, sobre os quais podemos apenas postular, aos mais recentes. Os estudos críticos modernos, e mesmo as adaptações de histórias mitológicas e épicas gregas na cultura pop atual, podem ser pensados como parte de uma mesma tradição, multimilenar. É verdade que em cada momento deste longo percurso a valorização da tradição e as próprias formas de transmissão foram diferentes, mesmo dentro de um mesmo contexto histórico. Ainda assim, essa longevidade não deixa de ser um elemento importante.

d) Tradição de transmissão de histórias em poesia épica hexamétrica grega (transmissão oral e escrita)

Da primeira delimitação de nossa tradição específica, parto para uma segunda. Trata-se da tradição de criação e transmissão de tais histórias na poesia épica hexamétrica grega. Também aqui, todavia, temos mais de uma possibilidade de transmissão. Temos a transmissão oral, de um lado, e a transmissão escrita, do outro, associada a um texto fixado. Trata-se, aqui, de outro fenômeno de longa duração. Mesmo hoje, além dos manuscritos de inúmeros períodos, os quais ainda temos e nos esforçamos em preservar, a prática de estabelecer edições dos textos de poesia épica hexamétrica permanece ${ }^{6}$. Tal prática atesta a existência ainda viva de uma tradição de transmissão dos textos que nos interessam.

fórmulas, temas, métrica, narrativa etc. O problema é que, ao invés de definir tradição, os homeristas tendem a reificá-la (Scodel, 2002: 3-4).

${ }^{6}$ Para citar algumas, o texto da Ilíada e da Odisseia, editados por Monroe e Allen (1920), ainda exerce grande influência. Thiel $(1996)$ e West $(1998,2000)$ apresentaram recentemente suas 
Essa tradição é relevante socialmente, à sua própria maneira, para cada período. Cada momento traz suas especificidades e elementos de interesse. Por isso, é preciso delimitar ainda mais.

e) Tradição de transmissão da poesia oral épica hexamétrica grega

Chego, por fim, à última delimitação da tradição que me interessa. Dentro de todas as camadas de tradição levantadas, trata-se da tradição de poesia oral grega épica hexamétrica. Mais do que isso, o escopo pode ser ainda mais restrito, abarcando somente dois de seus exemplares: a Ilíada e a Odisseia, os chamados poemas homéricos.

Várias dificuldades emergem do recorte. A principal delas talvez seja a de que temos acesso somente aos textos escritos. Ainda assim, eles apresentam, segundo as teorias mais difundidas atualmente, profundas marcas de oralidade ${ }^{7}$. Tentarei, a partir deste momento, mapear as principais características dessa tradição.

\section{A tradição oral da qual os poemas homéricos fazem parte}

\section{a) Temática}

Apesar das suas especificidades, um primeiro aspecto deve ser reconhecido. Ele coloca, justamente, os poemas homéricos em relação com as camadas anteriores de tradição. Usualmente, a despeito das posições adotadas pelos estudiosos e dos pressupostos assumidos quanto aos critérios de datação, aceita-se que os poemas não tenham surgido do vácuo, mas pertençam a uma tradição mais ampla e antiga ${ }^{8}$. Pode-se argumentar que os poemas sejam fruto da genialidade de um poetamestre, que compôs a Ilíada e a Odisseia, ou ainda fruto do trabalho de um poeta-mestre para cada um deles. Esse poeta pode ter composto oralmente, tendo sido seus resultados memorizados por seguidores que passaram a citar mais ou menos fielmente as criações de seu mentor ${ }^{9}$. Pode, alternativamente, ter recebido a ajuda de escribas, que fixavam na forma escrita o que era ditado no momento da composição ${ }^{10}$. Outra possibilidade é que os poemas já tivessem sido compostos com o uso da

edições da Ilíada. A Odisseia foi editada no fim do século XX de nossa era pelo mesmo Thiel (1991).

7 Este posicionamento é baseado especialmente nas propostas de Parry (1930; 1932) e Lord (1960).

${ }^{8}$ Até autores críticos da teoria de que os poemas sejam orais, como Ahl e Roisman, defendem que os poemas fazem parte de uma tradição mítica mais ampla (Ahl; Roisman, 1996: 16-18).

${ }_{9}^{9}$ Posição defendida por Kirk (1962) e Taplin (1992).

10 Posição defendida por Jensen (1980), Shear (2000) e Lord (1960). 
escrita ${ }^{11}$. Pode-se defender também que são resultado da junção de inúmeros poemas menores de proveniências diversas, editados por um compilador ${ }^{12}$. Pode-se, ainda, propor que sejam oriundos de composições e recomposições orais, realizadas durante longos períodos e por grande abrangência espacial, por bardos diferentes ${ }^{13}$. Pode-se, inclusive, sugerir que os poemas não sejam nem ao menos representativos dessa tradição, em virtude de sua qualidade estética superior, de sua estrutura, complexidade, extensão e unidade planejada ${ }^{14}$. Ou, finalmente, pode-se pensar que os poemas se contrapõem de maneira consciente e ativa às tendências anteriormente conservadas, propondo inovações e invenções particulares no desenvolvimento de suas tramas ${ }^{15}$.

A despeito da posição ou da combinação de posições assumida pelos estudiosos em algum ponto desses extremos, uma tradição mais ampla que existiu independentemente dos poemas é pressuposta. Mesmo que tenham surgido como maneira de se contrapor a tal tradição, os poemas são construídos de forma a deixar claro que fazem parte de um todo maior. O foco, tanto na Ilíada quanto na Odisseia, é voltado para tramas específicas. Mas, em vários momentos, os poemas evidenciam $\mathrm{o}$ pressuposto de que as audiências ou os leitores deveriam reconhecer esse universo mais amplo. Este universo continha outros episódios, outros personagens e, possivelmente, outras versões das histórias que nos chegaram nos poemas aqui estudados.

Do que se trata, portanto, essa tradição mais ampla referida na discussão acima apresentada? E de onde vêm os indícios de sua presença, além da existência dos poemas em questão? Ora, como venho tentando demonstrar, o conceito de tradição pode ser utilizado para nomear fenômenos diferentes, mas interconectados. Na presente discussão, a tradição relevante é a mais ampla, que trata da transmissão de histórias, mitos e episódios envolvendo personagens que fazem parte da formação e da ordenação do mundo e da idade heroica da Grécia. Na Antiguidade, essa tradição relacionada ao passado heroico era, muitas vezes, vista como verdade histórica, como parte real do passado grego.

O passado heroico era povoado por personagens que se envolveram em uma grande quantidade de episódios, lutando contra monstros (como Héracles, Perseu e Belerofonte), viajando e tomando parte em aventuras

\footnotetext{
11 Posição defendida por West $(2011 ; 2014)$ e A. Parry (1989:137).

12 Posição dos analistas. Ver em especial Wilamowitz (1991).

${ }^{13}$ Posição defendida por Nagy (1996).

${ }_{14}$ Rutherford se pergunta se a Ilíada e a Odisseia representariam a forma típica da tradição épica maturada ou seu expoente final (Rutherford, 1996: 5).

${ }^{15}$ Posição defendida por Russo (1968).
} 
(como os Argonautas) ou lutando em guerras, como as de Tebas e Troia. A Ilíada e a Odisseia dizem respeito ao último tipo. São particularmente associadas à guerra e ao retorno de Troia.

A tradição mais ampla representa, portanto, uma visão de um povo a respeito de seu passado heroico e mítico. Mais do que a visão acerca do passado apenas, a tradição diz respeito à transmissão dessa visão. A Ilíada e a Odisseia faziam parte dessa tradição. Também poderíamos incluir nela os poemas de Hesíodo, os hinos homéricos e os poemas do chamado "Ciclo Épico", que sobreviveram apenas como fragmentos e resumos.

Homero e Hesíodo ${ }^{16}$, em especial, eram considerados as autoridades quanto aos deuses, ao passado heroico e à história do cosmo, segundo Graziosi e Haubold. Os poetas compartilhavam não só uma técnica e ferramentas do épico em hexâmetro, mas uma visão do mundo e de como ele se transformou no tempo (Graziosi; Haulbold, 2005: 8). Contudo, essa não é a única forma de transmissão dessa visão do passado.

A pintura em cerâmica e outras formas de arte figurativa também registram a circulação dessa tradição, em versões possivelmente diferentes e independentes dos épicos que recebemos, sendo, contudo, partes de um mesmo contexto17. O culto aos heróis e suas tumbas apesar de uma origem diferente, relacionada ao culto aos antepassados em perspectivas locais - por vezes também se associaram a essa tradição, usando seus heróis como objetos de culto ${ }^{18}$.

Apesar de independentes, estas formas de transmissão - poesia, arte figurativa e culto heroico - também podem se relacionar. As variações dentro da tradição mais ampla podem criar tradições derivadas em si mesmas, ligadas por alguns elementos, mas independentes em outros, como na concepção que apresentei.

Por ora, é preciso deixar claro um primeiro pressuposto. Os poemas homéricos existem dentro de um complexo mais amplo, que denomino aqui de tradição de transmissão. Essa tradição comporta uma visão do passado, podendo ser compartimentada em outras formas tradições. Elas podem ser delimitadas tanto no que diz respeito ao conteúdo desse

\footnotetext{
16 Utilizarei o termo "Homero" para designar não necessariamente um possível poeta, mas sim os poemas homéricos. O mesmo é válido para o termo "Hesíodo".

17 Mesmo que seguissem ordenamentos particulares ao meio de transmissão, o paralelismo temático atesta algum tipo de relação entre os diferentes meios. Ver Malkin (1998: 38).

18 Para uma perspectiva contrária, ver Seaford (1994: 180-181). Ainian defende a perspectiva de que o culto heroico pode funcionar independentemente dos épicos, e práticas já existentes poderiam funcionar inclusive como exemplos que teriam influenciado a poesia (Ainiam, 1999: 33-35). O autor, portanto, reconhece a interação entre as diferentes formas de tradição.
} 
passado (mitológico ou histórico) quanto no que diz respeito à maneira como são transportadas (arte figurativa, culto aos heróis, poesia e outras formas de narrativa).

b) Longevidade da tradição: quando começou?

Uma vez reconhecida a abrangência da tradição, no sentido mais amplo do conceito, e sua aceitação como pressuposto, é preciso traçar seu alcance temporal, sua longevidade. Trata-se de um assunto complexo.

Identificar o início dessa tradição é a parte mais complicada. Podemos começar pela datação das cenas em arte figurativa. Os primeiros exemplares de cenas possivelmente relacionadas a temáticas épicas começam a surgir no século VIII ${ }^{19}$. Durante esse período, alguns outros exemplares podem dizer respeito à tradição de transmissão, mas essa atribuição é menos precisa ${ }^{20}$. O que a arte figurativa pode dizer acerca da datação é que a partir deste período, em especial a partir do século VII, existia a circulação da tradição mais ampla. Ela, contudo, não nos diz nada sobre seu início, que possivelmente antecede os exemplares sobreviventes, se não em arte figurativa, ao menos em outros meios.

Ao usar os marcos das tradições de transmissão iconográfica relacionadas ao mesmo contexto de histórias épicas e mitológicas, temos a indicação de que, após este período, a tradição de poesia épica hexamétrica já poderia estar presente e compartilhando de temáticas semelhantes. No entanto, tais exemplares não indicam que a tradição poética também tenha começado a ser transmitida ali. É possível que o grau de sofisticação apresentado nos poemas que temos exija certo tempo de desenvolvimento para ser atingido.

O mesmo pode ser dito das relações entre a tradição e algumas das primeiras inscrições alfabéticas. Existe a teoria, proposta em especial por Powell (1996), de que a escrita alfabética tenha sido introduzida na Grécia para fixar poemas épicos como os de Homero. O fato de algumas das mais antigas inscrições estarem em hexâmetros talvez seja um indício dessa relação ${ }^{21}$.

No caso da poesia, datar a composição ou a fixação dos poemas homéricos é tarefa difícil e ainda em debate. Vale a mesma indefinição em

\footnotetext{
${ }_{19}$ Para Snodgrass, uma voga iconográfica passageira, apesar de reconhecida em seis regiões da Grécia, figurava, provavelmente, os gêmeos siameses conhecidos como Actóridas. Para o autor, tal voga cessa no começo do século VII e tem seu início atestado em torno da metade do século VIII (Snodgrass, 2004: 42-62).

${ }^{20}$ Ver Snodgrass para um levantamento e balanço do problema (Snodgrass, 2004: 35-70).

${ }^{21}$ Wade-Gery é o precursor desta abordagem (Wade-Gery, 1952: 11-14).
} 
relação aos poemas de Hesíodo, aos hinos homéricos e do Ciclo Épico, pois sequer temos segurança em datá-los em relação a Homero 22 .

Estamos em um terreno no qual adentramos com pouca segurança. Em virtude de sua temática e da possibilidade de sobrevivência de uma série de elementos referentes à cultura material, de geografia política, de língua e até mesmo de organização social, há muito tempo se sugere que a tradição heroica e sua poesia épica tenha tido início no chamado mundo micênico. Tratei desses elementos de maneira mais pormenorizada em outra oportunidade ${ }^{23}$. Aqui, basta dizer que alguns elementos desse mundo poderiam ter sido transmitidos no interior dessa tradição. Apesar de ser uma posição antiga e amplamente difundida 24 , ela não é, todavia, unânime. Raaflaub a critica ao defender a possibilidade de que a tradição heroica tenha se desenvolvido durante o chamado Período Obscuro 25 como forma de explicar as impressionantes ruínas visíveis na época, referentes, supostamente, a um mundo heroico anterior (Raaflaub, 1998: 393-401). O fato de essas ruínas corresponderem ao mundo micênico seria mera coincidência.

A hipótese do autor deve ser levada em consideração. Mesmo que possamos aceitar a proveniência micênica de alguns vestígios materiais presentes nos poemas, é possível que eles sejam fruto de heranças e tesouros familiares, guardados e passados de geração para geração, associados em um período posterior de composição ao mesmo passado do mundo das grandiosas ruínas ${ }^{26}$. Em contrapartida, também devemos deixar em aberto a possibilidade de que a tradição tenha se iniciado no mundo micênico.

Como dito, este não é o mais seguro dos terrenos. O que deve ser ressaltado é que no início do século VII a tradição já estava presente de forma desenvolvida, sendo provavelmente fruto de um processo mais antigo. $\mathrm{O}$ alcance desse desenvolvimento, nos séculos anteriores, é o ponto mais difícil de identificar. No que diz respeito a uma estimativa mais próxima, podemos falar no fim do Período Obscuro e início do

\footnotetext{
22 O estudo de Janko é um dos mais citados (Janko: 1982). Ver também a coletânea de Andersen e Huag (2012).

${ }^{23}$ Ver Oliveira (2012).

${ }^{24}$ As posições mais radicais são de autores como Nilsson (1932; 1993), Page (1976), Luce (1975; 1998) e Shear (2000).

25 Apesar de polêmico, este termo permanece útil para designar os anos entre o colapso micênico e meados do século VIII. O período é obscuro para nós que temos poucas informações acerca dele. Para uma discussão sobre o tema, ver Desborough (1972: 11-12). Entre os arqueólogos, a proposta mais atual de nomenclatura para o período é a da "Idade do Ferro Inicial".

${ }^{26}$ Ver Grethlein (2010: 129).
} 
arcaico, entre os séculos IX e VIII. Se formos aceitar uma estimativa mais recuada, estamos falando de séculos de desenvolvimento, que remontariam ao mundo micênico entre seu auge e declínio, entre os séculos XIV e XII, ou mesmo além. O que tende para um lado ou para outro desses extremos pode ser resumido em duas posições: a aceitação de que os elementos reconhecidos como micênicos de fato tenham esse mundo como origem; a especulação de que tais elementos entraram nos poemas por outros meios.

c) Longevidade da tradição: quando terminou?

A tradição mais ampla de transmissão das histórias acerca dos heróis e dos mitos gregos nunca terminou. Como dito, ela continua viva. Mas este não é meu objeto de discussão. A parte da tradição que estou tentando delimitar é uma que diz respeito a um contexto, ou conjunto de contextos, e que é compreendida de maneira profundamente diferente de como hoje a compreendemos. As maneiras como lidamos com essas temáticas nos tempos modernos não são as mesmas, nem exercem as mesmas funções. A tradição, durante seu percurso, é encarada e pensada de acordo com particularidades de cada momento. Podemos dizer que interessa ao historiador entender por que cada época recebeu e transmitiu tais fenômenos de maneira específica em cada contexto.

Usarei três critérios para delimitar o alcance mais recente da parte da tradição que nos interessa. $\mathrm{O}$ primeiro diz respeito à maneira como os seus membros viam seu passado e se identificavam com ele, sendo a poesia épica um dos veículos desse processo. Portanto, um dos critérios para delimitar o alcance da tradição de transmissão pode ser estabelecido pela maneira por meio da qual a própria tradição era vista como mecanismo fiel de manutenção de um passado comum aos povos gregos.

Porém, tal recorte não restringe suficientemente a tradição em debate. Até mesmo Estrabão, no século I d.C., considerava Homero uma fonte confiável de informações sobre esse passado ${ }^{27}$, e tal confiança foi muito além. Mas é um primeiro critério: a tradição que estou tentando delimitar via no mundo heroico uma faceta real de seu passado, tal como evidenciado na postura de autores como Estrabão, Heródoto e Tucídides ${ }^{28}$.

O segundo critério diz respeito à transmissão oral dessa tradição, de maneira geral, e, mais especificamente, da transmissão e composição oral

\footnotetext{
27 Por exemplo em Estrabão I, 1. 2.

28 Tanto Heródoto quanto Tucídides apresentam elementos relacionados aos relatos homéricos como verdadeiros (Hdt. I, 3-5 e Tuc. I. 3. 2-4; 9-11).
} 
da poesia épica. Usarei como elemento delimitador o lugar da poesia oral na sociedade em questão. Mesmo com o advento da escrita, no século VIII, as formas orais de comunicação poética não foram imediatamente substituídas.

Tendo em vista o limite do letramento durante todo o período, as formas escritas de expressão, mesmo quando culturalmente predominantes, tinham a expressão oral em mente no momento de sua composição. Eram, em geral, escritas para serem lidas em voz alta, possivelmente em público ${ }^{29}$. Mas, em um momento entre os séculos V e IV, pode-se detectar que já havia uma maior valorização da cultura letrada no discurso da elite. No que diz respeito à poesia heroica épica e sua tradição, a partir desse momento a figura do bardo passou a ser aproximada à de um homem empobrecido, que canta para as classes mais baixas da população, enquanto as elites têm acesso a textos escritos de poemas épicos assim fixados ${ }^{30}$. Paralelamente à expansão da forma escrita de transmissão de nossos épicos, temos a figura do rapsodo. Aparentemente, os rapsodos transmitem o texto homérico de maneira diferente da dos aedos de um período anterior. Os rapsodos, em determinado momento, seriam recitadores de um texto teoricamente fixado e estabelecido ${ }^{31}$.

O terceiro critério de delimitação se baseia na associação dos poemas à figura de um autor, Homero, datável já no século VI. Sua posição de autor a ser reverenciado também é relevante. É verdade que o nome Homero pode ser uma forma de identificar a tradição, como foi sugerido por uma série de estudiosos ${ }^{32}$. A essa altura nossos poemas já são tidos como clássicos. Esse marco de delimitação é caracterizado pelo período no qual os poemas são transmitidos como textos fixados, não sendo mais recompostos em performance. Dessa forma, possíveis reinterpretações orais não seriam absorvidas nos poemas para a transmissão futura.

\footnotetext{
29 Para Taplin, nem mesmo o mais fervoroso defensor da composição escrita dos poemas homéricos expressaria que o poema foi composto para um público letrado e para ser lido (Taplin, 1992: 37).

30 Para Jensen, este fenômeno pode ser atestado do século IV em diante. Pode ser observado então um letramento das elites, uma valorização da cultura letrada e a associação da cultura oral com as classes inferiores, o que não era o caso anteriormente (Jensen: 1980, 125). Ver também Sealey (1957: 316, 342).

${ }^{31}$ Para Burkert, os rapsodos teriam substituído os aedos. Improvisação criativa teria dado lugar à reprodução de um texto fixado, aprendido de cor e disponível em livros. Burkert considera uma separação entre produção e simples performance, que teria ocorrido até o último terço do século VI, no mais tardar (Burkert, 1987: 48-49). Contudo, autores como Jensen (1980: 116-122) e West (2010: 2) defendem a hipótese de que os rapsodos ainda estariam associados a prática da composição criativa, e não só da recitação fixada.

32 Como Nagy (1996), em uma tradição que remonta, pelo menos, a Vico (2005: 873) e Wolf (1985). West sugere que uma guilda de rapsodos, os homeridai, teria adotado os dois poemas e os atribuído a seu ancestral mítico, ou seja, Homero (West, 1999: 2014, 43).
} 
Da maneira como interpreto os vestígios da tradição de transmissão da poesia épica, o que gostaria de deixar evidenciado é uma quebra na valorização da oralidade como mecanismo de transporte da tradição. A posição dos poemas homéricos como clássicos, como textos de autoridade, é importante, e foi assim que os textos nos alcançaram. Mas a tradição que busco delimitar é aquela que permite versões, variantes, outras canções, outros episódios, outros personagens. Nela, existiria uma variedade de cantores e de histórias concorrentes. Nela, os bardos não seriam relegados a uma posição marginal diante de uma sociedade cada vez mais letrada. Contudo, devemos reconhecer que, apesar das variações, a tradição de transmissão poética seria, em algum nível, coesa e reconhecida como parte de um mesmo fenômeno cultural.

Mesmo que o advento da escrita e seu desenvolvimento tenham ocorrido no interior do período delimitado e em paralelo com a tradição que descrevi, a forma como proponho identificar o alcance mais recente da tradição de transmissão poética em questão está associada à consideração da composição e da transmissão oral da poesia épica como formas social e culturalmente valorizadas. Portanto, marco o limite mais recente dessa tradição na existência atestada de uma transmissão textual escrita dos épicos que fosse predominante. Tal processo também pode ser demarcado pela desvalorização das formas orais de composição poética, relegadas a uma posição marginal ${ }^{33}$.

Com o desenvolvimento da cultura letrada, em dado momento a elite passou a valorizar mais outros tipos de elementos poéticos, relegando a cultura oral a certa marginalidade. Os bardos passariam a se dedicar ao entretenimento de parcelas mais baixas da população, diante da competição com textos escritos e fixados, inclusive da Ilíada e da Odisseia, do Ciclo Épico e dos hinos homéricos. A poesia oral passaria de manifestação dominante para manifestação marginal. Ela seria associada à memorização pura, à falta de criatividade e de genialidade, um fenômeno que contaminou inclusive a abordagem de parte dos estudiosos modernos.

d) Estatuto dos poemas homéricos no interior da tradição: têm posição de autoridade?

Já em um período recuado, os poemas homéricos foram considerados exemplares magistrais de sua tradição. Estudiosos modernos os

\footnotetext{
33 Ver Jensen (1980: 125-127). Para Ford, já no século V a cultura oral estava diminuindo e suas produções mais antigas estavam sendo avaliadas por novas ciências da linguagem, como a retórica e a filosofia (Ford, 1992: 3).
} 
selecionaram como as grandes obras de toda uma cultura ${ }^{34}$. Foram tanto apontados como os expoentes máximos da tradição quanto foram afastados dela por sua excepcionalidade ${ }^{35}$.

Será necessário, todavia, esperar o século VI para termos citações seguras do nome Homero e de sua relação com a poesia épica ${ }^{36}$. Durante parte da Antiguidade, outros poemas eram associados a tal nome, mas um processo de exclusão marcou a escolha da preferência cultural, relegando outros poemas a outros poetas, e isolando a Ilíada e a Odisseia como grandes obras atribuídas a um gênio: Homero. Contudo, este processo parece relativamente tardio ${ }^{37}$. Nas citações do século VI, "Homero" já aparece como um nome a ser reverenciado, talvez como um nome representativo do gênero épico de maneira mais ampla ${ }^{38}$. Essa tendência continua a ser observada em parte do século $\mathrm{V}$, mas há um claro movimento no qual os épicos considerados de maior qualidade vão sendo mais associados a Homero em detrimento dos demais épicos ${ }^{39}$.

Outro processo, que corre em paralelo ao descrito acima, também entre os séculos VI e V, pode ser observado na arte figurativa. Até o século VI, a preferência dos artesãos na escolha dos temas de suas obras não era a dos episódios narrados na Ilíada e na Odisseia ${ }^{40}$. Ainda que se possa argumentar que algumas obras tenham inspiração em episódios que são descritos ou mencionados nos poemas em questão, apresentados nesse meio alternativo com algumas variações, o que se observa é que os poemas não exerciam força de autoridade na escolha dos temas, nem na determinação de qual variante seria representada, quando existe associação temática.

\footnotetext{
${ }^{34}$ Ver Rutherford (1996: 5).

${ }^{35}$ Como, por exemplo, em Davies (1989: 8-10).

${ }^{36} \mathrm{Na}$ passagem do século VI para o V temos menções a Homero por Heráclito e Xenófanes preservadas em citações de autores tardios. O fragmento 30 de Heráclito é citado por Diógenes Laércio, o fragmento 21 é citado por Hipólito e o fragmento 63a é citado no escólio da Ilíada A T XVII 251 e por Eustácio (edição de Marcovich, 2007). No caso de Xenófanes, o fragmento 10 é citado por Herodiano e os fragmentos 11 e 12 são citados por Sexto Empírico (edição de Giannantoni, 1993). Para um levantamento das citações mais antigas de Homero, ver Burkert (1987: 44). Ver também West (1999).

37 Saïd defende que o corpus homérico antes de 520 era considerado mais amplo e incluía muitos outros poemas épicos, os hinos homéricos e paródias épicas, além da Ilíada e da Odisseia (Saïd, 2011: 17).

38 Ver Saïd (2011: 7) e Nagy (1996).

${ }^{39}$ De acordo com Graziosi e Haubold, tal processo parece ter estado em pleno desenvolvimento no século V e se acelerou no período helenístico, separando cada vez mais a Ilíada e a Odisseia dos demais (Graziosi; Haulbold, 2000: 25-26).

40 Ver a discussão em Snodgrass (2004), Friis Johansen (1967), Lowenstan (1992, 1997), Touchefeu-Meynieur (1968), Powell (1992) e Burkert (1987).
} 
O primeiro ponto fica claro se analisarmos a preferência dos episódios escolhidos, em que os personagens e cenas que figuram entre os mais populares não são centrais ou não aparecem em Homero. $O$ segundo ponto é explicitado diante da constatação de que, mesmo quando a escolha temática se encontra dentro do campo dos episódios descritos nos poemas, estes não seguem de maneira fiel o texto que nos alcançou. $\mathrm{O}$ episódio do ciclope Polifemo talvez seja uma exceção, com exemplares a partir de $670^{41}$, mas não há nenhuma comprovação de que eles fossem escolhidos em razão da posição da Odisseia dentro da tradição. É possível que a preferência dos artesãos seja pelo episódio em si, e não por um poema em especial que detenha posição de autoridade ${ }^{42}$.

Todavia, a partir do século VI, cada vez mais episódios dos poemas começam a figurar, especialmente na pintura de vasos. Esse processo se intensifica a partir da década de 20 daquele século e se mantém pelo século $\mathrm{V}$ adiante ${ }^{43}$. Ele apresenta fortes indícios de que a partir desses momentos os poemas, tais como os temos, ou versões muito semelhantes a eles, passaram a ser cada vez mais considerados fontes de autoridade para a escolha dos temas e das versões dos episódios a serem retratados, ainda que não de maneira exclusiva. É interessante notar a proximidade com as datas em que começamos a ter citações cada vez mais seguras do poeta Homero, associado cada vez mais à Ilíada e à Odisseia, em detrimento de outros épicos. O presente processo também parece ser um fenômeno que só alcançou relevância maior a partir do século VI. Antes desse período, se os poemas já existiam de maneira fixada, não estavam entre os preferidos dos artesãos e dos compradores de seus trabalhos, como critério para seleção de versões e de episódios heroicos a serem retratados na arte figurativa.

e) Diferentes tipos de poemas dentro da tradição oral épica hexamétrica

Propus uma ideia de tradição que pode ser subdividida em diversos outros tipos, inter-relacionados, mas até certo ponto independentes. Da concepção mais ampla, que abarca a transmissão como um todo das histórias sobre o passado heroico e à formação do mundo dos deuses e dos homens, delimitei, por fim, a tradição oral grega de poesia épica em hexâmetros.

\footnotetext{
${ }^{41}$ Ver Touchefeu-Meynieur, em especial o quadro 1 (Touchefeu-Meynieur, 1968: 304).

42 Para a posição contrária ver Rutherford (1996: 17) e Thouchefeu-Meynieur (1968). Já Malkin argumenta que, ainda no século V, quando já havia certamente textos da Ilíada e da Odisseia, as variantes na iconografia não deixaram de existir. Além disso, variações são detectadas do período geométrico ao romano, o que mostra a coexistência de formas, sejam elas textos fixos, imagens, canções improvisadas, etc. (Malkin, 1998: 42).

43 Ver em especial Friis Johansen (1967: 223-230) e Malkin (1998: 41).
} 
Do que trata essa poesia em particular, para além de sua métrica e temática? A delimitação passa necessariamente pelo critério da oralidade, pois outras poesias épicas em hexâmetro foram produzidas em outros períodos - como a Argonáutica, de Apolônio de Rhodes -, mas estas trazem formas de composição poética relativas à escrita ${ }^{44}$. Os outros poemas já citados, a Ilíada e a Odisseia, Os Trabalhos e os Dias e a Teogonia, os hinos homéricos e possivelmente os fragmentos do Ciclo Épico, a despeito de sua existência escrita (ou em trechos escritos), trazem possíveis marcas de oralidade. Se não foram compostos de maneira completamente oral, têm, ao menos, relação mais direta com tal tipo de tradição. Isso não quer dizer que sejam todos do mesmo tipo. O número de versos é um primeiro critério de diferenciação. A Ilíada e a Odisseia, individualmente, ultrapassam todos eles em termos de extensão. São monumentais se comparados com os demais ${ }^{45}$.

Já a escolha temática diferencia a Ilíada, a Odisseia e os poemas do Ciclo Épico dos outros. Os hinos homéricos parecem servir como mecanismos de introduzir os épicos homéricos, mesmo os hinos que têm maior extensão. Além disso, no caso destes, contam narrativas relacionadas com as origens ou episódios importantes da história dos deuses. Os poemas de Hesíodo mostram, entre outras temáticas, uma ordenação do mundo, falando de sua origem, eras e características. É evidente que em ambos os casos existem congruências com as temáticas heroicas desenvolvidas nos poemas homéricos, mas é importante ressaltar essa diferenciação de abordagem no interior de uma mesma tradição poética que compartilha um mesmo tipo de métrica e uma mesma forma de composição.

Os poemas do Ciclo Épico têm mais afinidade temática com os poemas homéricos. Ainda assim, com base nos resumos que temos deles, nos fragmentos e nos juízos que recebemos de autores posteriores, foram traçadas algumas distinções. A primeira delas já foi levantada: a extensão. As demais dizem respeito à língua épica e à qualidade estética ${ }^{46}$.

A despeito das diferenças de tipo, vale ressaltar novamente que todos eles compartilham uma mesma tradição. A ressonância entre eles pode

\footnotetext{
44 Ver Parry (1930: 74).

${ }^{45}$ A Cípria teria 11 cantos. A Etiópida e os Nostoi teriam 5 cantos cada e a Pequena Ilíada 4 . A Iliou Persis e a Telegonia teriam 2 cantos cada.

46 Ver Davies (1989: 1-10). Contudo, vale ressaltar que Davies se apoia fortemente em Aristóteles e em critérios estéticos marcadamente anacrônicos, se relacionados ao material que analisa. Para Scodel, muitos intérpretes modernos foram influenciados pela desaprovação estética que Aristóteles e Aristarco nutriam pelo Ciclo. Recentemente, alguns estudiosos têm tentado se desvencilhar desta posição, considerando os poemas do Ciclo produtos não necessariamente inferiores e secundários, mas representantes de uma tradição oral mais ampla (Scodel, 2011: 501-515).
} 
ser observada, a partir de vários pontos de vista, principalmente pelas referências compartilhadas entre si e pela pressuposição de que a audiência ou os leitores tenham a noção de um todo maior que abarca estes e outros temas, personagens e episódios.

f) Função da tradição: memória; integração cultural; pan-helenismo

A tradição mais ampla, da maneira como tem sido apresentada aqui, possui grande abrangência temporal, já que é de longa, ou mesmo longuíssima duração (a depender do critério de delimitação temporal aceito). Também abarca várias formas de expressão (poética de vários tipos, outros tipos de expressão oral, arte figurativa etc.).

No caso específico da poesia, seria possível identificar a função que exercia? A princípio, poderíamos listar o entretenimento como função. A poesia tem a clara intenção de ser esteticamente agradável, bem como entreter sua audiência ou leitor. Contudo, ela não era apresentada somente como forma de entretenimento.

Outra função seria a de repositório de memória coletiva. Para Luce, a ação dos bardos era uma forma de manutenção segura dessa memória. Com a ausência de ampla difusão de formas de escrita, os bardos exerciam uma função social ao transmitir e apresentar as tradições valorizadas pela comunidade (Luce, 1998: 9)47.

Tal conservação implica uma série de outras possíveis consequências. Por funcionar como mecanismo de memória cultural, a poesia seria também um mecanismo de integração cultural. Essa tradição conecta um espaço geográfico potencialmente amplo e sobrevive a um período que pode ser longo ou longuíssimo. Se compreendermos que a tradição mantém estável alguns de seus elementos, podemos pensar que a integração cultural funciona tanto na esfera espacial quanto na esfera temporal. $\mathrm{Na}$ poesia, seriam transportadas maneiras de ver o passado, compartilhadas por comunidades separadas pelo espaço e pelo tempo, mas unidas culturalmente por meio da valorização de uma mesma tradição poética.

Tal questão, abordada de maneira diferente, abrange o aspecto de um fenômeno cultural denominado pan-helenismo. Esse fenômeno pode ser observado em várias manifestações culturais, a partir, em especial, do século VIII. Além da língua, compartilhada desde muito tempo, nesse período outros elementos culturais passam a ser comuns. Um sentimento

\footnotetext{
47 Ver também Havelock, que entende os poemas homéricos como expressões de uma visão enciclopédica do mundo. A narrativa homérica estaria em contato contínuo com a organização e visões de mundo da sociedade (Havelock, 1996: 106-108).
} 
de unidade e integração cada vez mais desenvolvido pode ser percebido, a despeito das características locais que permaneciam relevantes ${ }^{48}$.

Entre as manifestações culturais pan-helênicas, poderíamos destacar os santuários que passam a assumir essa dimensão (Delfos, Delos, Dodona etc.) e os festivais (em Olímpia e outros) ${ }^{49}$. Os poemas da tradição oral épica, entre eles a Ilíada, a Odisseia e as variantes de ambas, ofereceriam às diferentes comunidades gregas histórias e deuses comuns, além da língua compartilhada ${ }^{50}$.

É possível que a memória cultural preservada pela poesia talvez preceda o movimento pan-helênico que se acelera a partir do século VIII. Como apresentei, essa memória pode trazer elementos do passado micênico, transportados inclusive durante o chamado Período Obscuro.

Se não aceitarmos as origens em um contexto tão recuado, mas uma tradição que começa a ser desenvolvida em algum momento mais próximo do fim do Período Obscuro, ela pode muito bem ser oriunda de manifestações locais, que passaram a se desenvolver em paralelo e por fim se fundiram como parte do processo de pan-helenismo acima desenhado.

g) Tradição estável ou em mudança constante?

A tradição de transmissão que estamos discutindo pode ser de longa ou longuíssima duração. Porém, uma série de problemas surge se nos propusermos a discuti-la de maneira mais ampla. Tais problemas provêm de uma primeira dificuldade: a qual período podemos atribuir a composição ou fixação dos poemas que temos no interior da tradição? Não é um assunto de que tratarei em detalhes.

Por ora, devo salientar que, a despeito de como seja abordada tal dificuldade, pode-se argumentar que os poemas que temos, a Ilíada e a Odisseia entre eles, podem ser lidos como testemunhos da tradição como um todo, além de fontes para os supostos períodos em que foram fixados ou compostos. Essa abordagem depende da maneira como encaramos o problema da estabilidade dentro da tradição.

\footnotetext{
${ }^{48}$ Ver Bouvier (2002: 444-445).

${ }^{49}$ Ver Snodgrass para uma discussão e levantamento de fenômenos (Snodgrass, 1971: 352-435).

50 O modelo de Nagy compreende a poesia pan-helênica como tipos de poesia e canção que operam não simplesmente em uma base local, apropriados para audiências locais. Ao contrário, a poesia pan-helênica seria o produto de uma síntese evolucionária de tradições poéticas, de forma que o que ela representa tende a ser comum à maior parte das localidades e particular de nenhuma (Nagy, 1990: 54).
} 
É importante deixar claro que não temos condições de estabelecer uma resposta definitiva. Dos poemas em si, temos alguns elementos que nos permitem inferir acerca de seu grau de estabilidade. A língua é um deles. Com o deciframento do Linear B ${ }^{51}$, ficou detectado que existem elementos do grego micênico sobreviventes no texto homérico, bem como existem também arcaísmos eólicos e jônicos ${ }^{52}$. A própria estrutura do sistema formular, ainda que tenha sido criticada e não seja mais aceita por vários especialistas nos moldes propostos por Parry, sugere que elementos podem ser mantidos de maneira mais ou menos fixa por longos períodos.

Quando Parry e Lord iniciaram, na década de 1930, os estudos comparativos tendo a tradição oral da então Iugoslávia como base, essa abordagem era extremamente inovadora ${ }^{53}$. Os resultados da comparação foram muito criticados por existirem limites que se referem a especificidades culturais e pela diferença do próprio tipo de tradição dos dois lados da comparação ${ }^{54}$. Algumas críticas foram virulentas, ao ponto de sugerir que o trabalho de campo com intenção de comparar tradições orais diferentes não seja útil para a análise literária dos poemas homéricos e da tradição grega de poesia épica ${ }^{55}$. Talvez a abordagem de Parry e Lord de fato tenha aceitado muitos elementos da tradição identificados na então Iugoslávia como passíveis de generalização para todas as tradições épicas orais. Talvez este seja o ponto mais frágil da proposição da chamada teoria oral formular em seus estágios iniciais.

Desde aquelas pesquisas iniciais, contudo, muitos outros pesquisadores passaram a se interessar por trabalho de $\operatorname{campo}^{56}$. Com a multiplicação das pesquisas em lugares extremamente variados, ficou detectado, o que não vem como grande surpresa, que a variedade de formas orais de composição épica tradicional é tão ampla quanto as formas de culturas em que tais manifestações estão ou estiveram presentes ${ }^{57}$.

\footnotetext{
51 Ver Chadwick (1995).

52 Ver Nagy (2011: 231-233).

${ }^{53}$ Os resultados f:ram publicados de maneira mais influente somente em The Singer of Tales de Lord, em 1960.

${ }^{54}$ Tais críticas aparecem já em Kirk (1962) e continuaram desde então.

55 Para Rutherford, o trabalho de Parry com tradições vivas é menos valioso do que sua análise do sistema formular (Rutherford, 1996: 14).

56 Ver, por exemplo, as coletâneas organizadas por Honko, Handoo e Foley (1998) e por Mundal e Wallendorf (2008).

$57 \mathrm{O}$ estudo mais influente a defender esta posição continua a ser o de Finnegan. Em geral, seu livro é um excelente exemplo de que se devem evitar generalizações no que concerne a definições acerca de poesias orais, além de apontar que não há uma diferenciação absolutamente clara entre literatura oral e escrita. Além disso, Finnegan deixa claro que um único modelo de composição em performance não é adequado para todos os casos (Finnegan: 1977: 69-87).
} 
Muitos estudiosos, não obstante, mantêm a prática de propor generalizações de alguns elementos referentes a culturas orais, e uma dessas generalizações recai sobre a questão da estabilidade possível no interior de uma tradição desse tipo. Uma posição comum defende que, no interior de uma tradição oral, só é possível manter uma memória do passado que tenha elementos (estruturas sociais, práticas, objetos) que atinjam, no máximo, três gerações ${ }^{58}$. Tal concepção é baseada na ideia de que o passado só é atingido enquanto existirem membros vivos que se lembrem dele, ou seja, ele depende da longevidade das gerações e de estruturas que permitam que avós passem experiências a seus netos. Por vezes adotam o conceito de homeostasis, o qual postula que, nas tentativas de uma tradição de falar de seu passado, o presente de qualquer cultura também é incluído, e com mais força do que o passado que teria a intenção de atingir ${ }^{59}$.

Ora, as análises comparativas entre tradições orais de origens diversas demonstraram grande variedade de tipos de tradição e de elementos que as compõem. Sobre a questão da estabilidade, de quanto uma tradição oral pode manter e transmitir de maneira mais ou menos fiel o seu passado, e qual é o alcance possível em relação a esse passado, é preciso analisar a importância dada no interior da tradição à maneira como ocorre sua transmissão.

Isto porque o grau de fixação do que é transmitido oralmente (se recomposto ou decorado) varia de tradição para tradição, e tal elemento depende da concepção que seus membros (bardos, contadores de histórias e audiência) têm do que é transmissão fiel, do que é considerado verdade e de sua estabilidade ${ }^{60}$. $\mathrm{O}$ que não pode ser tomado como pressuposto é a suposta limitação da memória sem o auxílio da escrita como instrumento fiel de manutenção estável de informações extensas. Tal concepção é alimentada por uma percepção do senso comum, de uma prática memorativa cotidiana de nossos contextos atuais. O que temos é que, pela existência plenamente difundida da tecnologia da escrita,

\footnotetext{
58 Ver por exemplo Raaflaub (1998: 394-396) e Saïd (2011: 77-79).

59 Ver Goody e Watt (1968), Ong (1982, 46-49) e Vansina (1965). Para os limites do conceito, ver o próprio Vansina, que defende que muitas vezes mudanças sociais levam a adições, e não supressão, o que deixaria formas variantes mais antigas intactas. Além disso, mesmo temas que tendem a ser suprimidos podem deixar traços (Vansina, 1985: 120-123).

${ }^{60}$ Ver Mundal e Wallendorf, em especial seus comentários sobre a poesia skaldica nórdica, que não permite muita variação, sendo geralmente memorizadas, palavra por palavra (Mundal; Wellendorf, 2008: 1-2).
} 
dependemos menos do uso exclusivo da memória, tendo suas potencialidades menos desenvolvidas ${ }^{61}$.

Isso não é necessariamente verdade para culturas exclusivamente ou prioritariamente orais, com difusão limitada da tecnologia da escrita. Nelas, feitos memorativos mais refinados e desenvolvidos poderiam atingir resultados potencialmente impressionantes para nossa percepção. Além disso, a ideia de homeostasis parece dar mais ênfase aos aspectos que de fato se transformaram durante a passagem do tempo em detrimento daquilo que pode ter permanecido, seja por esforço ativo, seja de maneira inconsciente ${ }^{62}$.

Não temos, contudo, como medir de maneira precisa o grau de estabilidade proporcionado pela tradição grega de composição poética oral da épica hexamétrica. Sequer sabemos o grau de importância dado à questão da transmissão fiel de um texto e a percepção de como os integrantes da tradição encaravam o que seria uma transmissão fiel. Podemos detectar, por exemplo, no aspecto linguístico, alguns elementos estáveis, se aceitarmos um início mais antigo para a tradição de transmissão poética. Todavia, o alcance desta estabilidade é discutível. No que diz respeito à descrição de estruturas e instituições sociais, que porventura tenham sido absorvidas e mantidas na transmissão dos poemas, a questão é ainda mais complicada, o que merece uma discussão à parte.

Entretanto, devo neste momento assumir como possibilidade que elementos de longa ou longuíssima duração podem ter sido absorvidos nos próprios poemas, no aspecto das formas de composição e integração cultural. Essa é uma das chaves de minha proposta de abordagem das fontes, em especial do ponto de vista da História. Nesse sentido, os poemas seriam encarados tendo em vista atingir a tradição da qual são oriundos.

Se essa tradição tem elementos que apresentam uma estabilidade grande e possam remontar a um passado longínquo, ou se ela diz respeito somente a uma releitura mais recente de tal processo, não podemos dizer ao certo. Eis um dos problemas centrais da área. Mas isso não impede

\footnotetext{
${ }^{61}$ Taplin vê na vertente que defende o uso da escrita na composição dos poemas homéricos um descrédito grande da memória no mundo ocidental contemporâneo, em que feitos complexos de memória, como a composição de um grande épico orgânico e extremamente arquitetado e estruturado, seriam impossíveis (Taplin, 1992: 36).

62 Ver Malkin (1998: 269-270). Para Scodel nem toda tradição é necessariamente homeostática (Scodel, 2002: 19).
} 
uma abordagem histórica dos poemas que leve essas características particulares da tradição em consideração.

\section{Referências Bibliográficas}

AHL, F.; ROISMAN, H. M. The Odyssey reformed. Ithaca: Cornell University Press, 1996.

AINIAM, A. M. Reflections on Hero Cults in Early Iron Age Greece. In: HÄGG, R. Ancient Greek Hero Cult: Proceedings of the Fifth International Seminar on Ancient Greek Cult. Stockholm: Paul Aströms Förlag, 1999.

ANDERSEN, O.; HUAG, D. (eds.) Relative Chronology in early Greek epic poetry. Cambridge: CUP, 2012.

BOUVIER, D. Le cetre et la lyre: L' Iliade ou les herós de la memoire. Grenoble: Jérôme Millon, 2002.

BRAUDEL, F. História e Ciências Sociais: A longa duração. In: Escritos sobre a história. São Paulo: Editora Perspectiva, 2009. p. 41-78.

BURKERT, W. The making of Homer in the sixth Century B.C.: Rapsodes versus Stesichorus. Papers on the Amasis Painter and His World. Malibu: Paul Getty Museum, 1987, p. 43-62.

CHADWICK, J. The decipherment of linear B. Cambridge: CUP, 1995.

DAVIES, M. The Greek Epic Cycle. Bristol Classical Press. 1989.

DESBOROUGH, V. R. The Greek Dark Ages. New York: St. Martin Press, 1972.

FINNEGAN, Ruth. Oral poetry: its nature, significance and social context. Cambridge: CUP, 1977.

FORD, A. Homer: the poetry of the past. Cornell: CUP, 1992.

FRANCISCO, Gilberto da Silva. Panatenáicas: tradição, permanência e derivação. Tese, MAE, 2012.

FRIIS JOHANSEN, K. The Iliad and the early Greek art. Copenhagen: Munksgaard. 1967.

GIANNANTONI, G. (ed.). I Presocratici: Testimonianze e frammenti. Bari: Laterza, 1993. 
GOODY, J.; WATT, L. The Consequences of Literacy. In: Goody, J. (ed.), Literacy

in

Traditional Societies, edited by J. Goody, pp. 27-68. Cambridge: 1968.

GRAZIOSI, B.; HAUBOLD, J. Homer: the resonance of epic. London: Duckworth, 2005.

GRETHLEIN, J. From 'imperishable glory' to History: the Iliad and the Trojan War. In: KONSTAN, D.; RAAFLAUB, K. A. (org.) Epic and history. Malden-Oxford: Wiley-Blackwell, 2010.

HAVELOCK, E. Prefácio a Platão. Campinas: Papirus, 1996.

HOBSBAWM, E; RANGER, T. (eds.). A invenção das tradições. São Paulo: Paz e Terra, 1997.

HONKO, I.; HANDOO, J.; FOLEY, J. M. (eds.). The Epic - Oral and Written. Mysore: Central Institute of Indian Languages, 1998.

JANKO, R., Homer, Hesiod, and the Hymns: diachronic developments in epic diction. Cambridge: CUP, 1982

JENSEN, M. S. The Homeric question and the oral formulaic theory. Copenhagen: Museum Tusculanum Press, 1980.

KIRK, G. The songs of Homer. Cambridge: CUP, 1962.

MUNDAL, Else; WELLENDORF, Jonas. Oral art forms and their passage into writing. Copenhagen: Museum Tusculanum Press, 2008.

LENCLUD, G. Qu'est-ce que la tradition? In: DETIÈNNE, M. (ed.) Transcrire les mythologies. Paris: Albin Michel, p. 25-44, 1994.

LORD, Albert Bates. The singer of tales. Cambridge: Harvard University Press, 1960.

LOWENSTAM, Steve. The Uses of Vase-Depictions in Homeric Studies. Transactions of the American Philological Association (1974-), vol. 122, 1992, p. 165- 198.

. Talking Vases: The relationship between the Homeric poems and archaic representations of epic myth. Transactions of the American Philological Association (1974-), v. 127, 1997, p. 21-76. 
LUCE, J. V., Homer and the Heroic Age. London: Thames and Hudson, 1975.

- Celebrating Homer's landscape: Troy and Ithaca revised. Yale University Press, 1998.

MALKIN, Irad. The returns of Odysseus: colonization and ethnicity. Berkeley: University of California Press, 1998.

MARCOVICH, M.; MONDOLFO, R.; TARÁN, L. Eraclito: Testimonianze, Imitazioni e Fragmmenti. Milano: Bompiani, 2007.

MONRO, D. B.; ALLEN, T. W. Homeri Opera. Oxford: Claredon Press. $3^{\text {a }}$ edição. 1920.

NAGY, G. Homer's Pindar. Baltimore: Johns Hopkins University, 1990. . Homeric Questions. Austin: University of Texas Press, 1996. . Homer the preclassic. Berkeley: University of California Press, 2011.

NILSSON, M. The Mycenaean Origin of Greek Mythology. Cambridge: CUP, 1932.

1993.

Homer and Mycenae. New York: Cooper Square Publishers, Inc.,

ONG, W. J. Orality and Literacy: The technologizing of the world. London: Methuen, 1982.

OLIVEIRA, Gustavo J. D. Histórias de Homero: Um balanço das propostas de datação dos poemas homéricos. Revista História e Cultura, Franca-SP. V. 1, n. 2, p. 126-147, 2012.

OUTHWAITE, W.; BOTTOMORE, T. Dicionário do pensamento social do século XX. Rio de Janeiro: Jorge Zahar editor, 1996.

PAGE, D. L. History and the Homeric Iliad. Berkley: University of California Press, 1976.

PARRY, Adam. The language of Achilles and other papers. Oxford: OUP, 1989.

PARRY, Milman. Studies in the Epic Technique of Oral Verse-Making I. Homer and Homeric Style. Harvard Studies in Classical Philology, v. 41, 1930, p. 73-147. 
Studies in the Epic Technique of Oral Verse-Making II. The Homeric Language as the Language of an Oral Poetry. Harvard Studies in Classical Philology, v. 43, 1932, p. 1-50.

PHILLIPS, M. S.; SCHOCHET, G. (eds.). Questions of Tradition. University of Toronto Press, 2004.

RAAFLAUB, K. A. Homer, the Trojan War, and History. In: BOEDECKER, D. The world of Troy. Washington, DC: Society for the Preservation of the Greek Heritage, 1998.

RUSSO, Joseph. Homer against his tradition. Arion, v. 7, n. 2, 1968.

RUTHERFORD, R. B. Homer. Oxford: OUP, 1996.

SEALEY, R. From Phemios to Ion. Revue des Études Grecques. Tome LXX, p. 312-355, 1957.

POWELL, B. Writing, oral poetry, and the invention of the narrative style in greek art. In: BUITON-OLIVER, D. (ed.) The Odyssey and Ancient Art: an epic in word and image. New York, Bard College, 1992, p. 180-185.

. Homer and the origin of Greek alphabet. Cambridge: CUP, 1996.

SAÏD, S. Homer and the Odyssey. Oxford: OUP, 2011.

SCODEL, R. Listening to Homer: Tradition, narrative and Audience. Michigan: UMP, 2002.

. Hesiod and the Epic Cycle. In: MONTANARI, F. RENGAKOS, A. TSAGALIS, C. C. (eds.) Homeric contexts: neo analysis and the interpretation of oral poetry. Berlin: De Gruyter, 2011.

SEAFORD, R. Reciprocity and Ritual: Homer and the tragedy of the developing City-state. Oxford: OUP, 1994.

SELIGMAN, E. R.; JOHNSON, A. Encyclopaedia of Social Sciences. New York: Macmillan Company, 1957, vol. 15.

SHEAR, I. M. Tales of heroes: the origins of Homeric texts. New York: Aristide D. Caratzas, 2000.

SHIELS, E. Tradition. Chicago, University of Chicago Press, 1981.

SNODGRASS, A. M. The Dark Age of Greece: An Archaeological Survey of the Eleventh to Eighth Centuries B.C. Edinburgh: University Pres, 1971. 
Homero e os Artistas: texto e pintura na arte grega antiga. São Paulo: Odysseus Editora, 2004.

TAPLIN, O. Homeric soundings: the shaping of the Iliad. Oxford: Claredon Press, 1992.

THIEL, H. van. Homeri Odyssea. Hildesheim: G. Olms, 1991. Homeri Ilias. Hildesheim: G. Olms, 1996.

TOUCHEFEU-MEYNIER, O. Thèmes odysséens dans l'art antique. Paris: Editions E. de Boccard 1968.

VANSINA, J. Oral tradition: A study in historical methodology. Chicago: Aldine, 1965. . Oral tradition as history. Wisconsin: UWP. 1985.

VICO, G. Ciência Nova. Calouste Gulbekian, 2005.

WADE-GERY, H. T. The poet of the Iliad. Cambridge: CUP, 1952.

WEST, M. L. Ilias. Vol. I. Stuttgart \& Leipzig: Bibliotheca Teubneriana, 1998.

. Ilias. Vol. II. München \& Leipzig: Bibliotheca Teubneriana, 2000.

. The invention of Homer. Classical quarterly, vol. 49, n. 2, 1999, p. 364-382.

Rhapsodes at Festivals. Zeitschrift für Papyrologie und Epigraphik. Band 173, 2010, p. 1-13.

. The making of the Iliad. Oxford: OUP, 2011.

. The making of the Odyssey. Oxford: OUP. 2014.

WILAMOWITZ, M. U. V. Homerische Untersuchungen. Berlin: Weidmann, 1991.

WOLF. Prolegomena ad Homerum. Princeton: PUP. 1985. 